\title{
Efecto del uso de hidrolizado enzimático de proteína de levadura sobre la fermentación y el perfil sensorial del vino
}

\section{Effect of the use of enzymatic hydrolysate of yeast protein on the fermentation and sensorial profile of wine}

\author{
P. Valencia, P. Rojas, C. Urbina, y A. Urtubia \\ Departamento de Ingeniería Química y Ambiental, Universidad Técnica Federico Santa María, Avenida España, 1680 Valparaíso, Chile
}

\begin{abstract}
Resumen. Se evaluó el uso de proteínas de levaduras como fuente de nitrógeno orgánica para la fermentación en reemplazo del diaminofosfato (DAP). Se utilizaron Saccharomyces cerevisiae autoclavadas y posteriormente hidrolizadas con $6.75 \mathrm{mAU} / \mathrm{g}$ de subtilisina a $\mathrm{pH} 8.0$ y $50^{\circ} \mathrm{C}$ hasta grados de hidrólisis de $5 \%$ y $15 \%$. Se fermentó mosto de Cabernet sauvignon con Saccharomyces cerevisiae a $28^{\circ} \mathrm{C}$ y $\mathrm{pH} 3.5$, utilizando como fuente de nitrógeno DAP (control) e hidrolizados proteicos de levadura (tratamientos). Se realizó un seguimiento de las fermentaciones midiendo ${ }^{\circ}$ Brix, azúcares reductores y grado alcohólico final. El grado alcohólico resultó en promedio $12^{\circ}$, mientras que los azúcares residuales fueron menores a $2[\mathrm{~g} / \mathrm{L}]$. No se observaron diferencias significativas entre el control y los tratamientos, lo cual implica que durante las fermentaciones con hidrolizado proteico de levaduras no hubo deficiencia de nitrógeno, por lo que se infiere que los péptidos del hidrolizado fueron metabolizados por las levaduras. Se realizaron análisis sensoriales y de compuestos volátiles de diferentes vinos elaborados con DAP e hidrolizado proteico de levaduras como fuente de nitrógeno. El uso de hidrolizado proteico de levaduras generó cambios significativos en el perfil de alcoholes superiores y ésteres del vino en comparación con el uso de DAP. El panel organoléptico detectó un mayor dulzor y menor acidez en los vinos que usaron hidrolizado en comparación con los producidos con DAP. La utilización de hidrolizado enzimático de proteínas de levadura como fuente de nitrógeno orgánica en la fermentación del vino es técnicamente factible y además beneficiosa para las propiedades organolépticas del vino.
\end{abstract}

\begin{abstract}
Yeasts from the wine fermentation were processed and used as nitrogen source to replace the diaminephosphate (DAP). Saccharomyces cerevisiae were autoclaved and later hydrolyzed to $15 \%$ of degree of hdyrolysis $(\mathrm{DH})$ at $\mathrm{pH} 8$ and $50^{\circ} \mathrm{C}$ by using $6.75 \mathrm{mAU} / \mathrm{g}$ of subtilisin. The experiments consisted in fermentations of Cabernet sauvignon with Saccharomyces cerevisiae at $28^{\circ} \mathrm{C}$ and $\mathrm{pH} 3.5$, using as nitrogen source DAP, as the control, and yeast hydrolysate (YH), as the treatment. Fermentations were characterized measuring ${ }^{\circ}$ Brix, redactor sugars and alcoholic degree. The average alcoholic degree was $12^{\circ}$ with residual sugar concentrations below $2 \mathrm{~g} / \mathrm{l}$. Empirical evidence of non-significant differences among experiments implies that there was no limitation by nitrogen and that the peptides from the $\mathrm{YH}$ were assimilated by yeasts. The volatile compounds and sensorial analysis indicated significant differences in higher alcohols and esters between control and treatments. Higher sweetness and lower acidity were detected in $\mathrm{YH}$ fermented wines compared with DAP fermented wines. The utilization of enzymatic hydrolysate of yeast protein as an organic nitrogen source for the wine fermentation is technically feasible and, in addition, beneficial for the organoleptic properties of wine.
\end{abstract}

\section{Introducción}

El permanente crecimiento de la industria del vino inevitablemente redunda en un incremento de los residuos consistentes en materia orgánica como el escobajo, el orujo y la borra. Los principales tratamientos para estos residuos son la elaboración de destilados de orujo y el uso de la borra como fertilizante [1]. Sin embargo, la borra puede ser perjudicial para la calidad del suelo debido a su característica ácida [1]. La borra tiene un especial potencial como subproducto de la fermentación, ya que contiene altas concentraciones de sales de tartrato y levaduras. Las levaduras tienen una composición rica en proteínas e hidratos de carbono, lo cual las convierte en una potencial fuente de nutrientes para aplicaciones en la industria alimentaria y agropecuaria. Una alternativa de tratamiento es la hidrólisis enzimática de proteínas, donde el producto final posee propiedades funcionales que mejoran su calidad ya que son beneficiosas para la salud [2]. Asimismo, para aumentar la biodisponibilidad de los nutrientes y optimizar el proceso de hidrólisis, es que se recomienda el uso de un pretratamiento de ruptura celular previo a la hidrólisis [2]. La fuente de nitrógeno más usada en la industria es el diaminofosfato o DAP, que corresponde a un compuesto inorgánico con una alta concentración de nitrógeno asimilable. En este 
trabajo se propuso elaborar un hidrolizado enzimático de proteínas de levadura y utilizarlo como fuente de nitrógeno orgánica en la fermentación del vino, en reemplazo del DAP. Se ha documentado que el uso de fuentes de nitrógeno orgánicas en la fermentación del vino tales como aminoácidos o mezclas de sales de amonio y aminoácidos permite un aumento en la generación de los compuestos volátiles (encargados en parte del aroma y sabor del vino), mejorando la percepción sensorial del mismo [3-5]. Otro de los efectos es una mayor velocidad en la formación de etanol, alcanzado el grado alcohólico deseado en menos tiempo $[5,6]$. Sin embargo, no se tiene certeza de que estos serían los efectos resultantes al utilizar el hidrolizado enzimático de levaduras como fuente de nitrógeno, ya que se trata de una mezcla de péptidos y aminoácidos, que podrían ser difíciles de asimilar por la levadura. En este estudio se busca establecer la factibilidad del uso del hidrolizado en los procesos de fermentación vínica, y determinar la relación que existe entre las variaciones en el tratamiento de la fuente de nitrógeno, que incluyen pretratamiento con ultrasonido y autoclave y la posterior hidrólisis enzimática de proteínas. Los efectos serán registrados en los parámetros a medir durante el seguimiento de la fermentación.

\section{Materiales y métodos}

\subsection{Materiales}

La levadura utilizada para la elaboración del hidrolizado fue Saccharomyces cerevisiae marca Lalvin tipo EC1118 para fermentación vínica, con un contenido de proteína de $32.53 \%$. La proteasa corresponde a substilisina de Bacillus licheniformis del preparado comercial Alcalase de Novozymes. En las fermentaciones se utilizó mosto de Cabernet Sauvignon del valle del Maule, Chile ( $\left.35^{\circ} 03^{\prime} 44.7^{\prime \prime} \mathrm{S} 71^{\circ} 16^{\prime} 18.7^{\prime \prime} \mathrm{W}\right)$.

\subsection{Preparación de hidrolizados proteicos}

Suspensiones de levadura al $20 \% \quad(\mathrm{~m} / \mathrm{m})$ fueron autoclavadas a $121{ }^{\circ} \mathrm{C}$ durante $15 \mathrm{~min}$ y posteriormente sometidas a ultrasonido en un equipo SONICS VCX130 durante un tiempo de $90 \mathrm{~min}$. La mezcla fue posteriormente sometida a proteólisis con $6.75 \mathrm{mAU} / \mathrm{g}$ de subtilisina a $50^{\circ} \mathrm{C}$ y pH 8.0 controlado mediante $\mathrm{pH}$-stat con el autotitulador Compact Titrator G20 Mettler-Toledo para obtener un hidrolizado al 15\% de grado de hidrólisis.

\subsection{Fermentaciones}

Las fermentaciones se realizaron en duplicado a $\mathrm{pH}$ 3.45 en cubas conteniendo $2.5 \mathrm{~kg}$ de uva desgranada y despalillada. La fermentación se inició agregando un inóculo de levaduras activas más el suplemento de nitrógeno para alcanzar los $250 \mathrm{mg} / \mathrm{l}$ en el mosto. Estos suplementos fueron DAP (control), aminoácidos (AA), mezcla 1:1 de DAP e hidrolizado proteico de levadura (H50) e hidrolizado proteico de levadura (H100). La mezcla de aminoácidos se preparó de acuerdo al protocolo propuesto por Barbosa [3]. Una vez finalizadas las fermentaciones se realizó secuencialmente el descube, prensado, sedimentación de la borra y finalmente precipitación de tartratos. Luego de la separación de las sales de tartratos se obtuvo el producto final.

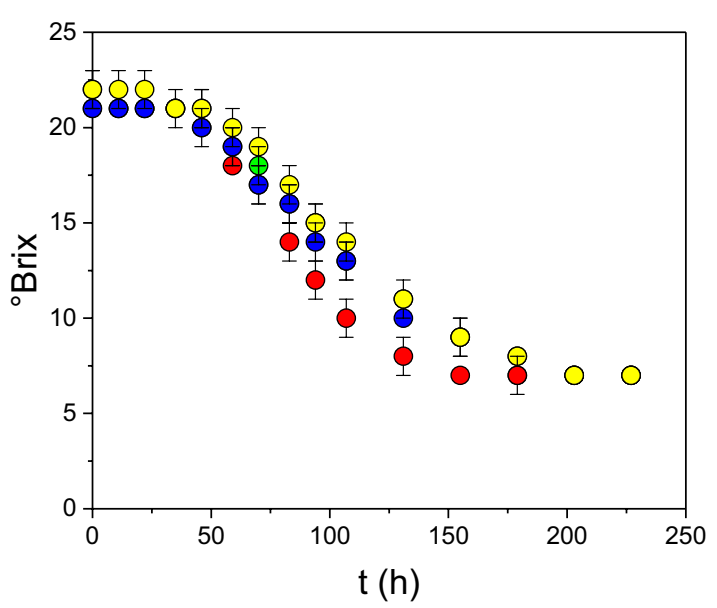

Figura 1. Progreso de ${ }^{\circ}$ Brix durante las fermentaciones con diferentes suplementos de nitrógeno. DAP (verde), AA (rojo), H50 (azul) y H100 (amarillo).

\subsection{Análisis químico}

Se determinaron parámetros generales de seguimiento de las fermentaciones grado alcohólico, $\mathrm{pH}$, acidez total y volátil, ácido tartárico, málico y láctico mediante espectrofotometría infrarroja con transformada de Fourier (FTIR). Los azúcares reductores se determinaron con el método del ácido dinitrosalicílico (DNS). Los compuestos volátiles mayoritarios 1-propanol, 2-metil-1-propanol, 2-metil1-butanol, 3-metil-1-butanol, 1-hexanol, 2-feniletanol, glicerol, metanol, acetato de etilo, lactato de etilo, succinato de etilo, acetoína, acetol, etanal y butirolactona se cuantificaron mediante cromatografía gaseosa (equipo Agilent 7890A) con detector de ionización por llama (FID).

\subsection{Análisis sensorial}

Se evaluaron los atributos aroma, acidez, dulzor, astringencia y color mediante un panel no experto capacitado para la detección de estímulo y la discriminación de niveles de intensidad con soluciones de ácido tartárico, sacarosa y ácido tánico. Se utilizó la prueba de clasificación simple y se analizaron los resultados mediante método paramétrico usando estadística de Friedman [7].

\section{Resultados y discusión}

Los experimentos de las fermentaciones se diseñaron para diferenciarse respecto de la fuente de nitrógeno con la que se suplementó el mosto al inicio de la fermentación. El progreso de las fermentaciones se siguió durante 10 días, tiempo al cual todas las fermentaciones presentaron un valor constante de ${ }^{\circ}$ Brix, tal como se observa en la Fig. 1.

Todas las fermentaciones progresaron a una velocidad similar, terminando todas al día 8 al mismo valor de ${ }^{\circ}$ Brix. Se observó que el experimento suplementado con aminoácidos tuvo una tasa de variación de ${ }^{\circ}$ Brix un poco mayor que el resto de los experimentos, siendo que a partir del día 6 no presentó más variación. En definitva, las fermentaciones progresaron adecuadamente y sin estancamiento, por lo que se infiere que no hubo limitación por nitrógeno y que las fuentes de nitrógeno orgánicas fueron asimiladas por las levaduras. A partir de 
Tabla 1. Valores de pH, grado alcohólico y azúcares reductores de los vinos preparados con los diferentes suplementos de nitrógeno.

\begin{tabular}{|c|c|c|c|}
\hline Experimento & $\mathbf{p H}$ & $\begin{array}{c}\text { Grado } \\
\text { alcohólico } \\
(\boldsymbol{\%} \mathbf{v} / \mathbf{v})\end{array}$ & $\begin{array}{c}\text { Azúcares } \\
\text { reductores } \\
(\mathbf{g} / \mathbf{l})\end{array}$ \\
\hline DAP & $3.51 \pm 0.01$ & $11.95 \pm 0.07$ & $1.43 \pm 0.08$ \\
\hline AA & $3.54 \pm 0.00$ & $12.00 \pm 0.28$ & $1.46 \pm 0.20$ \\
\hline H50 & $3.58 \pm 0.01$ & $12.10 \pm 0.14$ & $1.41 \pm 0.17$ \\
\hline H100 & $3.55 \pm 0.01$ & $12.00 \pm 0.49$ & $1.42 \pm 0.08$ \\
\hline
\end{tabular}

Tabla 2. Valores de acidez total y volátil de los vinos preparados con los diferentes suplementos de nitrógeno.

\begin{tabular}{|c|c|c|}
\hline Experimento & Acidez total (g/l) & Acidez volátil (g/l) \\
\hline DAP & $5.10 \pm 0.28$ & $0.46 \pm 0.02$ \\
\hline AA & $4.85 \pm 0.64$ & $0.68 \pm 0.04$ \\
\hline H50 & $4.45 \pm 0.07$ & $0.71 \pm 0.06$ \\
\hline H100 & $5.55 \pm 0.21$ & $0.66 \pm 0.01$ \\
\hline
\end{tabular}

estas fermentaciones se prepararon vinos que se analizaron químicamente para caracterizar su perfil molecular. $\mathrm{El} \mathrm{pH}$, grado alcohólico y azúcares reductores se muestran en la Tabla 1.

Los parámetros generales resultaron adecuados y sin diferencias significativas entre los diferentes tratamientos. Esto reafirma lo anteriormente inferido respecto de que el uso de hidrolizado proteico de levaduras no afecta el correcto progreso de la fermentación. En la Tabla 2 se observa que la acidez total y volátil resultaron en el rango adecuado. No se observó correlación entre la acidez total y los tratamientos. En tanto se observó que el uso de nitrógeno orgánico incrementa la acidez volátil respecto del uso de DAP. Los valores de $0.7 \mathrm{~g} / \mathrm{l}$ de acidez volátil se encuentran en el límite entre el umbral de percepción (0.4-0.7 g/l) y el de complejidad (0.7-1.1 g/l).

En la Tabla 3 se muestran los resultados obtenidos del análisis químico de compuestos volátiles. Los alcoholes superiores presentaron diferencias en todos los vinos. Sin embargo, no se aprecia correlación ente los valores de concentración y los tratamientos, por lo que no se logra inferir un efecto progresivo del uso de las fuentes de nitrógeno orgánico. Lo mismo se observó con los ésteres, en donde no se obtuvo un efecto progresivo con todos los suplementos de nitrógeno orgánico. Los alcoholes metanol y glicerol no presentaron diferencias entre los tratamientos. El único efecto significativo observado se obtuvo con la acetoína, en donde con las fuentes de nitrógeno orgánicas se produjo un incremento en la concentración de este compuesto. En la evaluación sensorial se obtuvo que el vino preparado con el suplemento H50 (50\% DAP, 50\% Hidrolizado proteico) presentó las calificaciones más bajas de astringencia y acidez, y la más alta para dulzor. La percepción de menos ácido de este vino con suplemento
Tabla 3. Concentración de compuestos volátiles en vino con diferentes suplementos de nitrógeno.

\begin{tabular}{|l|c|c|c|c|}
\hline \multirow{2}{*}{ Compuesto } & \multicolumn{4}{|c|}{ Concentración (mg/l) } \\
\cline { 2 - 5 } & DAP & AA & H50 & H100 \\
\hline 1-Propanol & 67.8 & 59.5 & 52.2 & 46.6 \\
\hline 2-Metil-1-Propanol & 71.5 & 91.7 & 94.0 & 76.8 \\
\hline 2-Metil-1-Butanol & 60.5 & 54.8 & 62.3 & 73.3 \\
\hline 3-Metil-1-Butanol & 231 & 189 & 236 & 260 \\
\hline 2-Feniletanol & 62.8 & 38.7 & 68.4 & 68.4 \\
\hline 1-Hexanol & 2.16 & 2.65 & 2.28 & 2.25 \\
\hline Metanol & 91.7 & 92.2 & 97.5 & 94.5 \\
\hline Glicerol & 8620 & 8020 & 9270 & 8830 \\
\hline Acetato de etilo & 109 & 183 & 143 & 134 \\
\hline Lactato de etilo & 4.26 & 6.51 & 10.17 & 3.89 \\
\hline Acetaldehído & 75.8 & 93.5 & - & 90.7 \\
\hline Acetoína & 5.6 & 8.8 & 12.5 & 7.01 \\
\hline
\end{tabular}

H50 coincide con el resultado analítico de menor acidez total (Tabla 2). El mayor dulzor de este vino también coincide con el resultado analítico del glicerol (Tabla 3).

\section{Conclusión}

Se constató experimentalmente que el uso de hidrolizado proteico de levadura es efectivo como fuente de nitrógeno durante la fermentación. No se logró constatar un efecto de la fuente de nitrógeno sobre el perfil molecular debido a que las variaciones de los compuestos volátiles no se correlacionaron con los tratamientos. Sin embargo, la apreciación sensorial indicó que hubo una influencia positiva en la calidad del vino preparado con fuente de nitrógeno orgánica. La verificación de estos resultados preliminares requiere de un mejor diseño estadístico que permita evidenciar algún efecto de la fuente de nitrógeno utilizada durante la fermentación.

\section{Referencias}

[1] B. Pérez-Bibbins, A. Torrado-Agrasar, J.M. Salgado, R.P. De Souza, J.M. Domínguez, Waste Manage. 40 (2015)

[2] H.G. Kristinsson, B.A. Rasco, Food Sci. Nutr. 40 (2000)

[3] C. Barbosa, A. Mendes-Faia, A. Mendes-Ferreira, Int. J. Food Microbiol. 160 (2012)

[4] D. Torrea, C. Varela, M. Ugliano, C. Ancin-azpilicueta, I.L. Francis, P.A. Henschke, Food Chem. 127 (2011)

[5] S. Bell, P.A. Henschke, Aust. J. Grape Wine Res. 11 (2005)

[6] E. Albers, C. Larsson, G. Lidén, C. Niklasson, L. Gustafsson, Appl. Envir. Microbiol. 62 (1996)

[7] M. Meilgaard, B. Carr, G. Civille, Sensory Evaluation Techniques (CRC Press, 2007) 